\title{
Measurements of diffusion coefficient of methane in water/brine under high pressure
}

\author{
Yen-An Chen, Che-Kang Chu, Yan-Ping Chen, Lee-Shin Chu, Shiang-Tai Lin, and Li-Jen Chen * \\ Department of Chemical Engineering, National Taiwan University, Taipei City, Taiwan
}

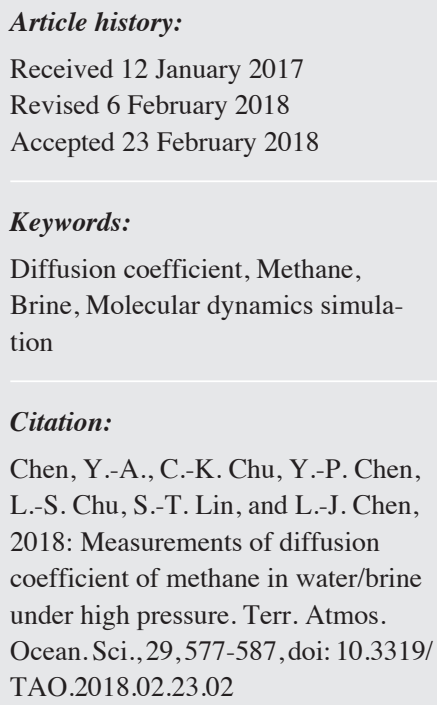

\begin{abstract}
The diffusion coefficient of methane in water plays an important role in the formation and dissociation of methane hydrate. However, most of the previous studies on the diffusion coefficient of methane in brine are performed at room temperature and low pressures, which is quite different from the formation condition of methane hydrate. In this study, we measure the diffusion coefficient of methane in pure water and brine in capillary tube at $10.3 \mathrm{MPa}$ and temperature ranging from 283.15 to $308.15 \mathrm{~K}$. We use the Raman spectrum to measure the ratio of C-H bound signal of methane to the $\mathrm{O}-\mathrm{H}$ bound signal of water, to estimate the concentration of methane dissolves in water/brine. The Raman spectrum is collected at different time and different positions away from the liquid-gas interface. Diffusion coefficient is determined by fitting the experimental data with the concentration profiles solved from Fick's second law and semi-infinity boundary condition. By this method, we can evaluate the diffusion coefficient at different temperatures or salinities. The diffusion coefficient of methane in water/brine increases as the temperature increases. The diffusion coefficient of methane in brine is lower than that in pure water. Molecular dynamics (MD) simulation is also performed in this study to calculate the diffusion coefficient of methane in water/brine. The MD results can successfully predict the tendency of temperature effect and adding electrolyte.
\end{abstract}

\section{INTRODUCTION}

Natural gas hydrate is considered to be a potential unconventional energy resource (Sloan and Koh 2007). The thermodynamic properties of natural gas hydrate have been extensively explored, such as phase boundary (Van Der Waals and Platteeuw 1958; Barrer and Ruzicka 1962a; Dalmazzone et al. 2002; Anderson et al. 2009; Hsieh et al. 2012; Chu et al. 2015, 2016; Juan et al. 2015), volumetric properties (Hester et al. 2007; Manakov et al. 2011; Ning et al. 2015), and dissociation enthalpies (Handa 1986; Rydzy et al. 2007; Gupta et al. 2008). Other physical properties of hydrate had been systematically reviewed (Sloan 1998; Gabitto and Tsouris 2010). Besides, some studies investigated the reaction kinetics of hydrate formation such as induction time and growth rate (Barrer and Ruzicka 1962b; Pinder 1965; Vysniauskas and Bishnoi 1983; Christiansen and Sloan 1994; Natarajan et al. 1994; Kashchiev and Firooza-

\footnotetext{
* Corresponding author

E-mail:ljchen@ntu.edu.tw
}

badi 2002a, b, 2003).

It has been pointed out that the formation and dissociation of hydrate is a diffusion-controlled process. Diffusion coefficient of methane in sea water is the controlling parameter in the dissociation process of methane hydrate in seabed sediment (Rehder et al. 2004) and in the migration of methane in marine (Egorov et al. 1999; Lin et al. 2006). Besides, diffusion coefficient of gas is necessary for engineers to carry out the gas-liquid mass transfer calculations and correlations (Himmelblau 1964). Therefore, the diffusion coefficient of methane in brine at the hydrate formation and dissociation condition (i.e., at high pressures) is essential in the engineering process design of methane production out of methane hydrate bearing sediment. There are some measurements on the diffusion coefficient of methane in water in the literature. The capillary cell method incorporated with gas chromatography was applied to measure the diffusion coefficients for methane, ethane, propane and butane in water (Witherspoon and Saraf 1965). Gubbins and coworkers used the diaphragm method to measure the diffusion coefficients 
for gases in water and in brine (Gubbins et al. 1966; Tham et al. 1967; Tham and Gubbins 1972). The diffusion coefficients for gases in liquids have been measured by some other methods, such as the inverted tube method (Maharajh and Walkley 1973), the flow method with pulse injection and detect the dispersion peak by differential refractometer (Pratt et al. 1973), the modified Barrer method (Jähne et al. 1987), and the time-resolved pressure detection method (Sachs 1998). More recently Chou and coworkers proposed a new method to measure the diffusion coefficients for gases (methane, $\mathrm{CO}_{2}$ and ethane) in water loaded inside a capillary tube at high pressures by using Raman spectroscopy (Lu et al. 2006, 2013; Guo et al. 2013; Lin et al. 2014). However, most of the experimental results of diffusion coefficients for gases in water/brine were performed at atmospheric pressure (Witherspoon and Saraf 1965; Maharajh and Walkley 1973; Pratt et al. 1973; Jähne et al. 1987). Some experimental works of diffusion coefficients were carried out at high pressures, but only limited to gases in pure water (Sachs 1998; Lu et al. 2006; Guo et al. 2013).

In this study, the diffusion coefficients of methane in pure water and in brine are determined at $10.3 \mathrm{MPa}$ and temperature ranging from 283.15 to $308.15 \mathrm{~K}$ by using the Raman spectroscopy. Instead of using experimental method of Lu et al. (2006) to assemble a capillary tube for the diffusion coefficient measurement at high pressures, we propose a simplified method to assemble the capillary tube for the Raman spectroscopy measurements.

\section{EXPERIMENTAL}

\subsection{Materials}

Water was purified by double distillation and then followed by a PURELAB Maxima Series (ELGA Labwater) purification system with the resistivity always better than 18.2 M $\Omega \cdot \mathrm{cm}$. The methane gas was purchased from Praxair with a purity of $99.97 \%$. Electrolytes $\mathrm{NaCl}, \mathrm{NaBr}, \mathrm{NaI}$, and $\mathrm{CaCl}_{2} \cdot 2 \mathrm{H} 2 \mathrm{O}$ with a purity of $99.5 \%$ were purchased from Merck.

\subsection{Experimental Setup}

The experimental setup for the measurement of the diffusion coefficient of methane in water/brine under high pressure is schematically illustrated in Fig. 1. Fused silica capillary tube $(150 \mu \mathrm{m}$ inner diameter and $360 \mu \mathrm{m}$ outer diameter, Polymicro Technologies) with standard polyimide coating was used as the diffusion cell in this study. The capillary tube was cut into $8-\mathrm{cm}$ pieces and the protecting polyimide coating outside the capillary tube was removed by alcohol burner. Water (or brine) was loaded into the capillary tube by dipping one end of the capillary tube into water (or brine). The water (or brine) in the capillary would rise rapidly due to the capillary force. About half of the capillary tube was filled with liquid and the liquid gas interface is located in the viewing window where the polyimide protecting layer was already removed to make sure the gas-liquid interface could be observed by the CCD camera. The end of the capillary tube with liquid was sealed by acetylene flame and the other end was hooked up with Micro Tight Adapter and then connected to a pressurization system (the syringe pump, Teledyne Isco 65D) via Swagelok connector. The photo of the assembled capillary tube is shown in Fig. 2.

This assembled capillary tube was then mounted onto the temperature control platform with a thermostatted water temperature circulated by thermostatic water bath circulator (Thermo Haake DC30-k20) and the temperature of sample capillary tube was monitored by a Yokogawa TX10 thermal couple with a accuracy of $0.1^{\circ} \mathrm{C}$ (calibrated by a quartz thermometer, HP2804a, Hewlett-Packard Co.).

The Raman system includes a Raman spectrometer with focal length of 1000 mm (FHR 1000, Horiba), Raman probe (Superhead, Horiba) with Charge-coupled Device (CCD) camera (SYN-1024x256-OE, Synapce), and high power laser (532 nm wavelength and $800 \mathrm{~mW}$ ), as the part number 6, 7, and 9, respectively, illustrated in Fig. 1. The objective is M Plan Apo SL50x purchased from Mitutoyo, the slit is $300 \mu \mathrm{m}$ controlled by the spectrometer. The filter is $532 \mathrm{~nm}$ laser line filter provided by omega optical. The position of the Raman probe can be controlled by stepping motor with a minimum step of $2.5 \mu \mathrm{m}$.

\subsection{Spectra Collection}

The syringe pump was maintained at $10.3 \mathrm{MPa}$ (= $1500 \mathrm{psi}$ ) methane gas. Then the valve between the syringe pump and the capillary tube was open to pressurize the capillary tube up to $10.3 \mathrm{MPa}$. It took less than 1 minute for the pressure to stabilize at $10.3 \mathrm{MPa}$. Raman spectrum of methane dissolved in water in the capillary tube was collected as a function of time. Each acquisition time was $50 \mathrm{sec}$ with two accumulations using an 1800 groove $\mathrm{mm}^{-1}$ grating with a spectral resolution of $1 \mathrm{~cm}^{-1}$. The Raman spectrum with wavenumber ranging from 2500 to $3950 \mathrm{~cm}^{-1}$ was collected as demonstrated in Fig. 3. The Raman spectrum was integrated to calculate the peak area. The broad peak ranging from 2750 to $3850 \mathrm{~cm}^{-1}$ was attributed to $\mathrm{O}-\mathrm{H}$ stretching of water, which can be further deconvoluted into 5 sub-band based on the local hydrogen bond (Sun 2009), and the small peak ranging from 2890 to $2930 \mathrm{~cm}^{-1}$ was attributed to C-H bond in methane (symmetric stretching vibration), as the red area shown in Fig. 3. The ratio of these peak area extracted from Raman spectrum had been extensively applied to quantitatively determine the concentration of certain species in the system (Wopenka and Pasteris 1986). That is, the ratio of these two Raman peak areas is directly proportional to the ratio of concentrations (in mole fraction) of two species. 


$$
\frac{A_{A} \sigma_{r, A\left(\bar{v}_{A}\right)}}{A_{B} \sigma_{r, B\left(\bar{v}_{B}\right)}}=\frac{C_{A}}{C_{B}}
$$

Where $A_{A}$ and $A_{B}$ are the peak area for a certain vibrational mode of species A and B, respectively, $\sigma_{r, A\left(\bar{v}_{A}\right)}$ and $\sigma_{r, B\left(\bar{v}_{B}\right)}$ are the relative normalized differential Raman scattering cross section for vibrational mode species $\mathrm{A}$ and $\mathrm{B}$, at a wave number $\bar{v}_{B A}$ and $\bar{v}_{B}$, respectively, and $C_{A}$ and $C_{B}$ are concentration of species $\mathrm{A}$ and $\mathrm{B}$, respectively, in mole fraction.

Note that Liu et al. (2012) pointed out that Raman signals of dissolved $\mathrm{CO}_{2}$ do not correlate strictly linearly any- more for $1 \mathrm{M} \mathrm{NaCl}$ aqueous solution. On the other hand, Caumon et al. (2014) pointed out that the salinity effect on the variation of $\mathrm{CH}_{4} / \mathrm{H}_{2} \mathrm{O}$ peak area ratio as a function of methane concentration is negligible when the salinity is low $(<4 \mathrm{~m})$ and the $\mathrm{CH}_{4} / \mathrm{H}_{2} \mathrm{O}$ peak area ratio dependence of methane concentration is linear at low methane concentration $(<0.2 \mathrm{~m})$. Therefore, Eq. (1) is applied to determine the methane concentration in the pure water as well as brine system.

Raman spectrum of methane dissolved in water was collected at different times and positions from the methane-liquid interface. For the pure water systems, the Raman spectra

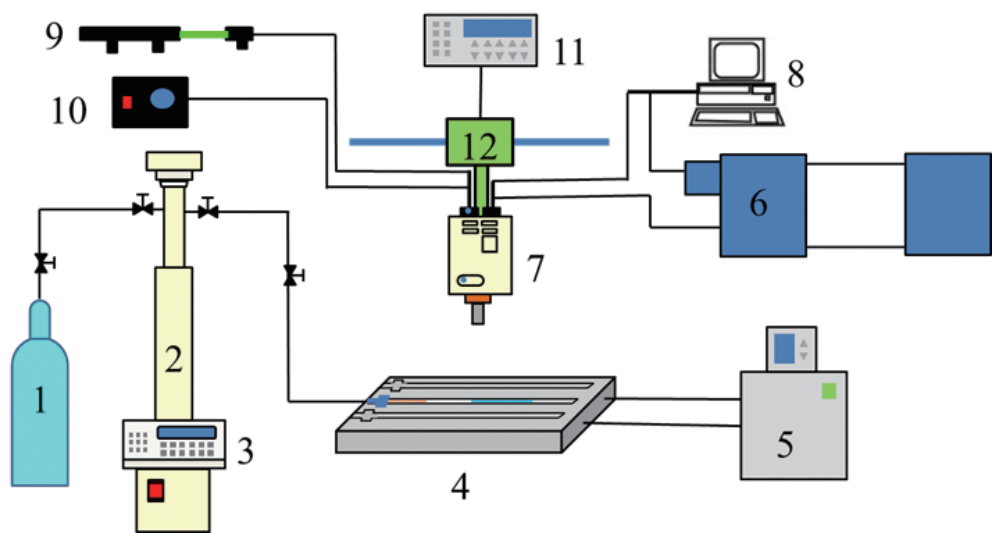

Fig. 1. Schematic diagram of experimental system. (1) Methane cylinder; (2) Syringe pump (Teledyne Isco 65D); (3) Syringe pump controller; (4) Temperature control platform; (5) Thermostatic water bath; (6) Raman spectrometer (FHR 1000, Horiba); (7) Raman probe (SuperHead, Horiba) with Charge-coupled Device (CCD) camera (SYN-1024x256-OE, Synapce) integrated by an X50 objective lens (Mitutoyo); (8) Personal Computer; (9) Laser light source; (10) Video light source; (11) Stepping motor controller; (12) Stepping motor.

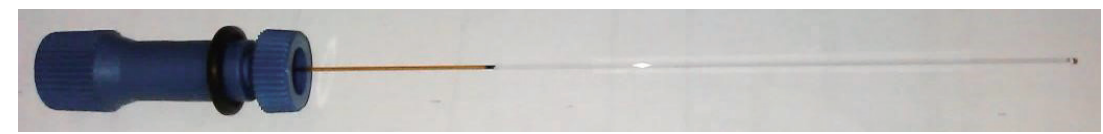

Fig. 2. Photo of an assembled capillary tube. The end on right-hand side was sealed by acetylene flame and the other end (left-hand side) was hooked up with the Micro Tight Adapter.

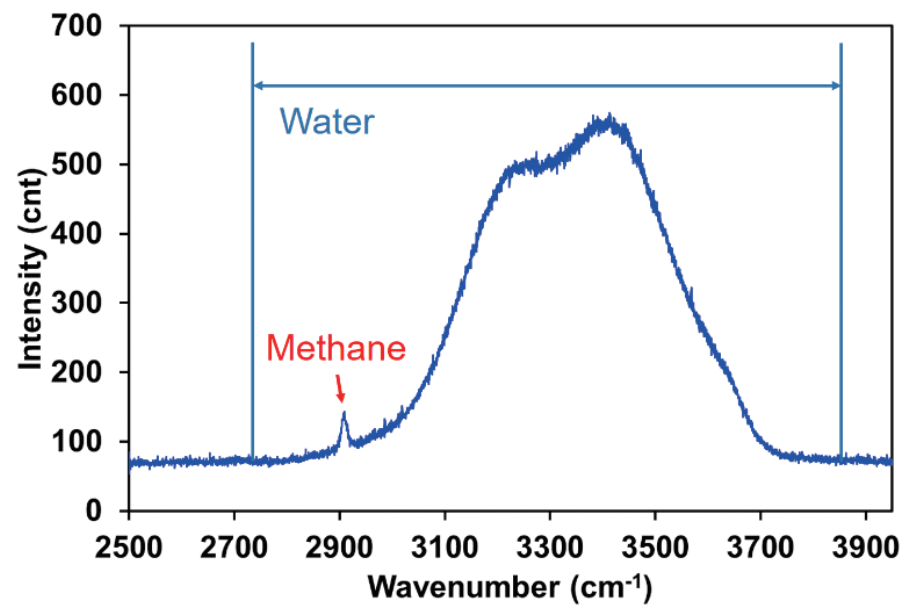

Fig. 3. Raman spectrum of methane dissolved in water. 
were collected at $0.250,0.500$, and $0.750 \mathrm{~cm}$ away from the gas-liquid interface and at $0.125,0.250,0.375$, and $0.500 \mathrm{~cm}$ away from the gas-liquid interface for the brine systems. The measurement of the time dependence of concentration would be completed within $10 \mathrm{hr}$ usually. The Raman spectrum near the gas-liquid interface (less than $125 \mu \mathrm{m}$ away from the gasliquid interface) was measured after three days, which would be treated as the Raman spectrum of saturated methane solution at prescribed system condition (pressure, temperature and salinity). The temperature control platform (part number 4 illustrated in Fig. 1) was housed inside an environmental chamber and the temperature control system would keep working throughout the whole experimental duration.

\subsection{One-Dimensional Diffusion}

In this study, when the capillary tube is pressurized up to $10.3 \mathrm{MPa}$ by methane, the methane-water (vapor-liquid) interface is generated and initiated to dissolve methane across the interface into water (or brine). Methane then diffuses along the capillary tube driven by the chemical potential gradient, which is proportional to the concentration gradient for ideal mixture (Bird et al. 2007). The combined flux $N_{A z}$ (number of moles of A that go through a unit area in unit time) in $\mathrm{z}$ direction can be expressed as,

$N_{A z}=-c D_{A B} \frac{\partial x_{A}}{\partial z}+x_{A}\left(N_{A z}+N_{B z}\right)$

The solubility of methane in water (or brine) is rather low (Duan and Mao 2006) therefore the advection contribution (second term in the right hand side) caused by diffusion can be neglected (Bird et al. 2007; Incropera et al. 2007). Since the inside diameter of the capillary tube is much smaller than the length of the capillary tube, the diffusion of methane along the capillary tube is assumed to obey the one-dimensional Fick's second law,

$\frac{\partial C}{\partial t}=\frac{\partial}{\partial z}\left(D \frac{\partial C}{\partial z}\right)$

where $D$ is the Fickian diffusion coefficient.

There are three boundary conditions used in this study. (1) The concentration of methane at the vapor-liquid interface is assumed to be constant, which is equal to the saturated concentration of methane $C_{0}$ at system condition (temperature, pressure, and salinity). (2) The diffusion coefficient of gas in liquid is low, so the penetration length is much smaller than the length of the capillary tube. Therefore, semi-infinity boundary condition is assumed. (3) In addition, there is no methane dissolved into water (or brine) before the system is pressurized (Bodnar and Himmelblau 1962). These three boundary conditions correspond to the following equations:

$\left\{\begin{array}{l}C=C_{0} \text { at } z=0, t>0 \\ C=0 \text { at } z \rightarrow \infty, t>0 \\ C=0 \text { at } t=0, z \geq 0\end{array}\right.$

The analytical solution of the Eq. (3) with the boundary conditions, Eq. (4), yields a complementary error function (Bodnar and Himmelblau 1962; Welty et al. 2007)

$\frac{C}{C_{0}}=\operatorname{erfc}(\eta)$

where $\eta$ is a dimensionless term $\eta=\frac{z}{\sqrt{4 D t}}$.

Equation (5) is then applied to determine the diffusion coefficient of methane in water by numerical data regression of the experimental data of methane concentration as a function of time extracted from Raman spectra.

\subsection{Molecular Dynamics Simulation}

The diffusion coefficient of methane in water and brine is also estimated by molecule dynamics (MD) simulations using GROMACS 4.5 (Berendsen et al. 1995; Van Der Spoel et al. 2005; Pronk et al. 2013). The force field used in this study is OPLS-aa (Jorgensen et al. 1996), except for water where the TIP4P-ICE model is used. The cutoff radii for nonbond interactions is $1 \mathrm{~nm}$. Long range Coulomb interactions are determined using the particle-mesh Ewald (PME) (Darden et al. 1993) method. The simulations are conducted under constant temperature and pressure [isothermal-isobaric (NPT) ensemble]. Nose-Hoover thermostat is applied to control the temperature and Parrinello-Rahman method is applied to the pressure control. The system contains 1000 water molecules, 11 electrolyte atoms, and 6 methane molecules. Periodic boundary condition is applied in all three dimensions. Equation of motion is calculated using leapfrog algorithm with an integration time step of $1 \mathrm{fs}$. The total simulation time is $100 \mathrm{~ns}$. The diffusion coefficient is calculated every $10 \mathrm{~ns}$ after the first $30 \mathrm{~ns}$ (equilibration) using the mean square displacement method of the molecules, as shown in Eq. (6).

$D_{s}=\frac{1}{6} \lim _{t \rightarrow \infty} \frac{\left\langle r(t+\Delta t)-\left.r(t)\right|^{2}\right\rangle}{\Delta t}$

where $D_{s}$ is the self-diffusion coefficient and $r(t)$ is the vector of position.

The self-diffusion diffusion coefficient calculated from Eq. (6) can be converted to Fickian diffusion coefficient by Eq. (7). 
$D_{A B}=\left(x_{A} D_{B}+x_{B} D_{A}\right)\left[1+\left(\frac{\partial \ln \gamma_{A}}{\partial x_{A}}\right)\right]$

where $D_{A B}$ is Fickian diffusion coefficient of A species in $\mathrm{B}, x_{A}$ and $x_{B}$ are the mole fraction of component $\mathrm{A}$ and $\mathrm{B}$, respectively, $D_{A}$ and $D_{B}$ are the self-diffusion coefficient of component $\mathrm{A}$ and $\mathrm{B}$, respectively, and $\gamma_{\mathrm{A}}$ is the activity coefficient of component A.

The differential of activity to concentration is determined by the predictive activity coefficient model, COSMO-SAC model (Hsieh and Lin 2011).

\section{RESULTS AND DISCUSSION}

\subsection{Diffusion Coefficient of Methane in Water at $10.3 \mathrm{MPa}(=1500 \mathrm{psi})$}

The peak area ratio of methane peak and water peak is divided by that measured at saturated methane condition that yields the dimensionless concentration, defined by methane concentration relative to saturated concentration, $C / C_{0}$. Figure 4 shows variation of the dimensionless concentration of methane in water at three different distances from the vapor-liquid interface as a function of time at $298.15 \mathrm{~K}$. The diffusion coefficient is then determined by least square fitting Eq. (5) to experimental data of dimensionless concentration vs time, as the solid curves illustrated in Fig. 4. Diffusion coefficient ranging from $1 \times 10^{-6}$ to $5 \times 10^{-4} \mathrm{~cm}^{2} \mathrm{~s}^{-1}$ is substituted into Eq. (5) and the root mean square deviation is calculated for each diffusion coefficient. The diffusion with the least deviation is the best fitted diffusion coefficient. The uncertainty with $95 \%$ confidence is determined by half of distance with double of least deviation (Guo et al. 2013).

A series of experiments of Raman spectroscopy on methane in water loaded in the capillary tube at $10.3 \mathrm{MPa}$, temperature ranging from 283.15 to $308.15 \mathrm{~K}$ were performed, and the results of the diffusion coefficient are listed in Table 1. Figure 5 shows the results of the diffusion coefficient of methane in water in this study in comparison with that of literature data (Witherspoon and Saraf 1965; Gubbins et al. 1966; Tham et al. 1967; Maharajh and Walkley 1973; Pratt et al. 1973; Jähne et al. 1987; Sachs 1998; Lu et al. 2006; Guo et al. 2013). It is obvious that the diffusion coefficient of methane in water rises along with an increase in temperature. It should be noted that some experiments of these previous studies have been performed at atmospheric pressure (Witherspoon and Saraf 1965; Gubbins et al. 1966; Tham et al. 1967; Maharajh and Walkley 1973; Pratt et al. 1973; Jähne et al. 1987) and the others at high pressures (Sachs 1998; Lu et al. 2006; Guo et al. 2013). Figure 5 reveals that the diffusion coefficient is not sensitive to pressure and our experimental results are consistent with that of previous studies within the experimental error. Note that our experimental results have an excellent agreement with that of Maharajh and Walkley (1973) and Guo et al. (2013). On the other hand, the results of Gubbins et al. (1966) are always slightly larger than our experimental results.

The variation of diffusion coefficient of methane in water as a function of temperature can be described by Eq. (8) (Himmelblau 1964).

$\ln D /\left(10^{5} \mathrm{~cm}^{2} / \mathrm{s}\right)=\frac{A}{T / K}+B$

where the parameters $A=-1990 \pm 213$ and $\mathrm{B}=7.11 \pm 0.72$ with $\mathrm{R}^{2}=0.95$ for our experimental results of methane diffusion coefficient in water, as the red solid curve illustrated in Fig. 5.

On the other hand, the diffusion coefficient can also be predicted by Hayduk and Laudie's (1974) correlation,

$D_{A B}=\frac{13.26 \times 10^{-5}}{\mu_{B}^{1.4} V_{A}^{0.589}}$

where $D_{A B}$ is Fickian diffusion coefficient of A species in $\mathrm{B}\left(\mathrm{cm}^{2} \mathrm{~s}^{-1}\right), \mu_{B}$ is the solvent viscosity (cP), $V_{A}$ is the molar volume at normal boiling point of solute, for methane $V_{A}=$ $37.7 \mathrm{~cm}^{3} \mathrm{~g}^{-1} \mathrm{~mol}$.

The pressure effect on diffusion coefficient is taken into account via the solvent viscosity in Eq. (9). In general, the pressure dependence of viscosity of liquids is very weak. For example, the difference between viscosities of water measured at 0.1 and $10 \mathrm{MPa}$ in the temperature range $25-50^{\circ} \mathrm{C}$ is always smaller than $0.2 \%$ (Schmelzer et al. 2005). Similarly, the pressure dependence of viscosity of $\mathrm{NaCl}$ aqueous solution is very weak (Kestin et al. 1978a). Consequently, the pressure effect on diffusion coefficient is weak enough to be neglected.

The viscosity of pure water is calculated by using the correlation of Kestin et al. (1978a, b), which covers the range $273.15-313.15 \mathrm{~K}$ with an uncertainty of $0.05 \%$. The prediction results of diffusion coefficient of methane in pure water from Eq. (9), as the red dashed line illustrated in Fig. 5, are consistent with our experimental results at low temperatures and slightly larger than our experimental results at high temperatures.

\subsection{Diffusion Coefficient of Methane in Brine at $10.3 \mathrm{MPa}$ (= $1500 \mathrm{psi})$}

The diffusion coefficient measurements are also performed for methane in $6.5 \mathrm{wt} \% \mathrm{CaCl}_{2}, 3.5 \mathrm{wt} \% \mathrm{NaCl}, 6.0$ wt $\% \mathrm{NaBr}$, and $8.6 \mathrm{wt} \% \mathrm{NaI}$ aqueous solution at $10.3 \mathrm{MPa}$ and temperature ranging from 288.15 to $308.15 \mathrm{~K}$. Note that the mole fraction of cation in these electrolyte solutions is fixed at 0.011 , a constant value. The experimental results of diffusion coefficient of methane in these electrolyte 


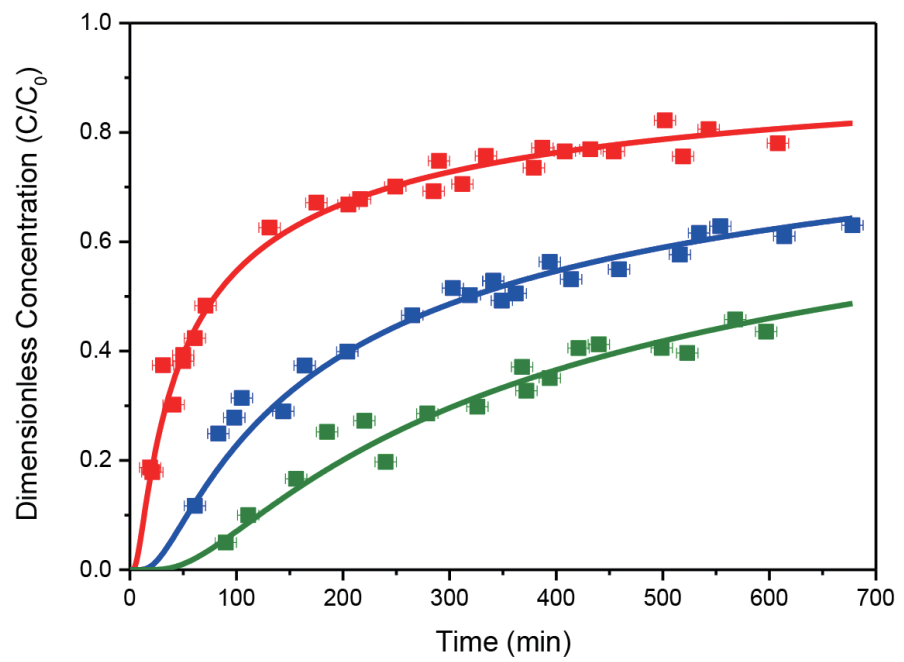

Fig. 4. Dimensionless concentration profiles of the diffusion process of methane in pure water at 298.15 K and 10.3 MPa. Dimensionless methane concentration were determined at $2.50(\square), 5.00(\square)$, and $7.50 \mathrm{~mm}(\square)$ from the vapor-liquid interface. Solid curves are the regression results of Eq. (5) with $\mathrm{D}=1.66 \times 10^{-5} \mathrm{~cm}^{2} \mathrm{~s}^{-1}$.

Table 1. Experimental results of diffusion coefficient of methane in water.

\begin{tabular}{ccc}
\hline Temperature (K) & Diffusion coefficient $\left(\mathbf{c m}^{2} \mathbf{~ s}^{-1}\right)$ & Uncertainty $\left(\mathbf{c m}^{2} \mathbf{s}^{-1}\right)$ \\
\hline 283.15 & $1.12 \times 10^{-5}$ & $2.9 \times 10^{-6}$ \\
293.15 & $1.38 \times 10^{-5}$ & $3.1 \times 10^{-6}$ \\
298.15 & $1.44 \times 10^{-5}$ & $1.1 \times 10^{-6}$ \\
303.15 & $1.71 \times 10^{-5}$ & $3.6 \times 10^{-6}$ \\
308.15 & $2.04 \times 10^{-5}$ & $3.7 \times 10^{-6}$ \\
\hline
\end{tabular}

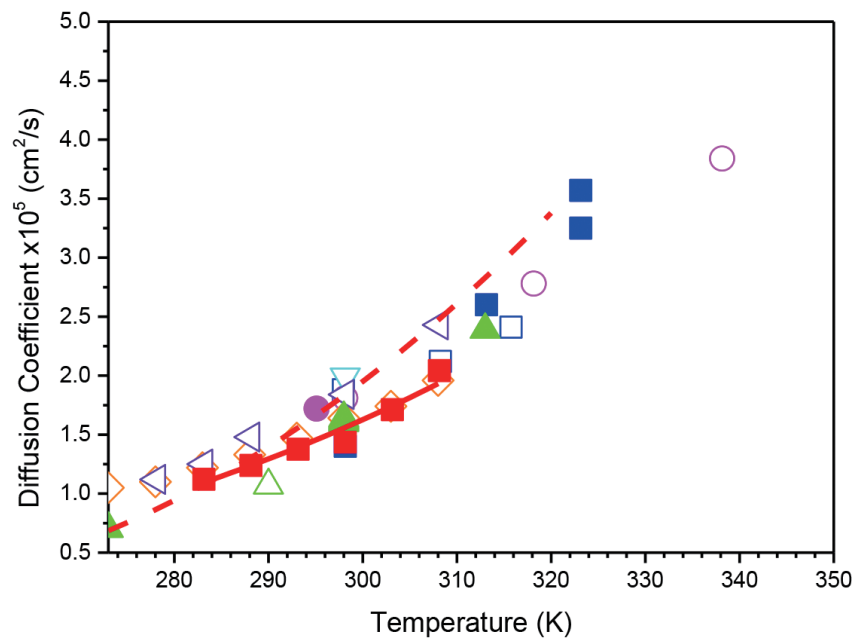

Fig. 5. Comparison of experimental results of diffusion coefficients of methane in pure water in this study with that of literature data. $\square$, experimental results in this work; $\square$ (Witherspoon and Saraf 1965); ○ (Gubbins et al. 1966); $\Delta$ (Pratt et al. 1973); $\nabla$ (Tham et al. 1967); $\diamond$ (Maharajh and Walkley 1973); $\triangleleft$ (Jähne et al. 1987); (Sachs 1998); (Lu et al. 2006); and $\Delta$ (Guo et al. 2013). Red solid line stands for the calculated results from Eq. (8). Red dashed line represents the prediction results from the correlation of Hayduk and Laudie (1974). 
solutions at $10.3 \mathrm{MPa}$ and temperature ranging from 288.15 to $308.15 \mathrm{~K}$ are reported in Table 2 and compared with the results of pure water in this study in Fig. 6. All the diffusion coefficients of methane in brine are consistently lower than that in pure water. For the fixed mole fraction of electrolyte, the capability of electrolyte to suppress diffusion coefficient of methane in brine is in the order of $\mathrm{CaCl}_{2}>\mathrm{NaI} \sim \mathrm{NaBr}>$ $\mathrm{NaCl}$. That is, the diffusion coefficient of methane in $\mathrm{CaCl}_{2}$ aqueous solution is the lowest among these electrolyte solutions, and that in $\mathrm{NaCl}$ aqueous solution is the highest among these electrolyte solutions. It should be pointed out that the diffusion coefficients of methane in brine at atmospheric pressure measured by Tham and Gubbins (1972), which had a higher concentration of $\mathrm{NaCl}$ than that in this study, are higher than the result in this study. However, the diffusion coefficient of methane in pure water measured by the diaphragm method (Gubbins et al. 1966; Tham et al. 1967) is also higher than that measured by Raman spectroscopy in this study and Guo et al. (2013), as mentioned above. Thus, the difference between the results of this study and the results of Tham and Gubbins (1972) might attribute to the systematic deviation between different methods.

On the other hand, the tendency of temperature effect on the diffusion coefficient of methane in brine is rather similar to that in pure water. Therefore, Eq. (8) is also applied to correlate the experimental data and the parameters A and B in Eq. (8) for the diffusion coefficient of methane in these electrolyte solutions are also listed in Table 3.

Hayduk and Laudie's (1974) correlation, Eq. (9), is also applied to predict the methane diffusion coefficient in brine. Viscosity of electrolyte solution is calculated by model of Laliberté (2007) with standard deviation of 3.7\%. The dashed lines shown in Fig. 6 stand for the prediction results from Eq. (9). Hayduk and Laudie's correlation successfully predicts the suppression of methane diffusion coefficient due to addition of electrolyte. However, the diffusion coefficients of methane in brine predicted from Eq. (9) are higher than the experimental results of this work. Besides, the prediction result of adding $\mathrm{CaCl}_{2}$ is higher than that of adding $\mathrm{NaCl}$, which is also different from the experimental results.

\subsection{Comparison with Molecular Dynamics Simulations}

The Fickian diffusion coefficient of methane in water and brine calculated by MD simulations is shown in Fig. 6 . The calculated diffusion coefficients are found to be consistently lower than experimental values because of the lowered pure water diffusivity using TIP4P-ICE water model. For example, the diffusion coefficient of TIP4P-ICE water is $1.33 \times 10^{-5} \mathrm{~cm}^{2} \mathrm{~s}^{-1}$ at $298.15 \mathrm{~K}$, which is about half of the experimental value $2.34 \times 10^{-5} \mathrm{~cm}^{2} \mathrm{~s}^{-1}$. Nevertheless, MD simulations correctly provides the relative change of methane diffusivity as a result of change in the electrolytes and temperatures. Other water models may provide higher accuracy in water diffusivity; however, the TIP4P-ICE model has the advantage of providing more accurate ice and hydrate melting temperature and methane solubility in water (Wu et al. 2016). Our results show that the TIP4P-ICE water model can provide useful qualitative information for consistency check with experiments. Considering its efficiency in time and cost, we believe that MD simulations can provide useful information regarding the effect of salt and temperature on methane diffusivity in more complex situations (e.g., mixed electrolytes) before conducting actual experiment.

\section{CONCLUSION}

The diffusion coefficient of high pressure methane in water and brine is measured in this study. The diffusion coefficient of methane in water measured in this study

Table 2. Experimental results of diffusion coefficient of methane in brine.

\begin{tabular}{c|ccc}
\hline solution & Temperature $(\mathbf{K})$ & Diffusion coefficient $\left(\mathbf{c m}^{2} \mathbf{s}^{-1}\right)$ & Uncertainty $\left(\mathbf{c m}^{2} \mathbf{s}^{-1}\right)$ \\
\hline & 283.15 & $1.13 \times 10^{-5}$ & $2.7 \times 10^{-6}$ \\
& 288.15 & $1.22 \times 10^{-5}$ & $3.4 \times 10^{-6}$ \\
$\mathrm{NaCl} 3.5 \mathrm{wt} \%$ & 298.15 & $1.29 \times 10^{-5}$ & $2.9 \times 10^{-6}$ \\
& 308.15 & $1.89 \times 10^{-5}$ & $4.5 \times 10^{-6}$ \\
\hline & 283.15 & $6.17 \times 10^{-6}$ & $1.8 \times 10^{-6}$ \\
& 288.15 & $7.97 \times 10^{-6}$ & $1.9 \times 10^{-6}$ \\
$\mathrm{CaCl}_{2} 6.5 \mathrm{wt} \%$ & 298.15 & $1.11 \times 10^{-5}$ & $3.7 \times 10^{-6}$ \\
& 288.15 & $8.87 \times 10^{-6}$ & $1.7 \times 10^{-6}$ \\
& 298.15 & $1.21 \times 10^{-5}$ & $3.7 \times 10^{-6}$ \\
$\mathrm{NaBr} 6.0 \mathrm{wt} \%$ & 308.15 & $1.49 \times 10^{-5}$ & $3.9 \times 10^{-6}$ \\
& 288.15 & $9.22 \times 10^{-6}$ & $2.7 \times 10^{-6}$ \\
\hline \multirow{2}{*}{$\mathrm{NaI} 8.6 \mathrm{wt} \%$} & 308.15 & $1.46 \times 10^{-5}$ & $6.1 \times 10^{-6}$ \\
\hline
\end{tabular}




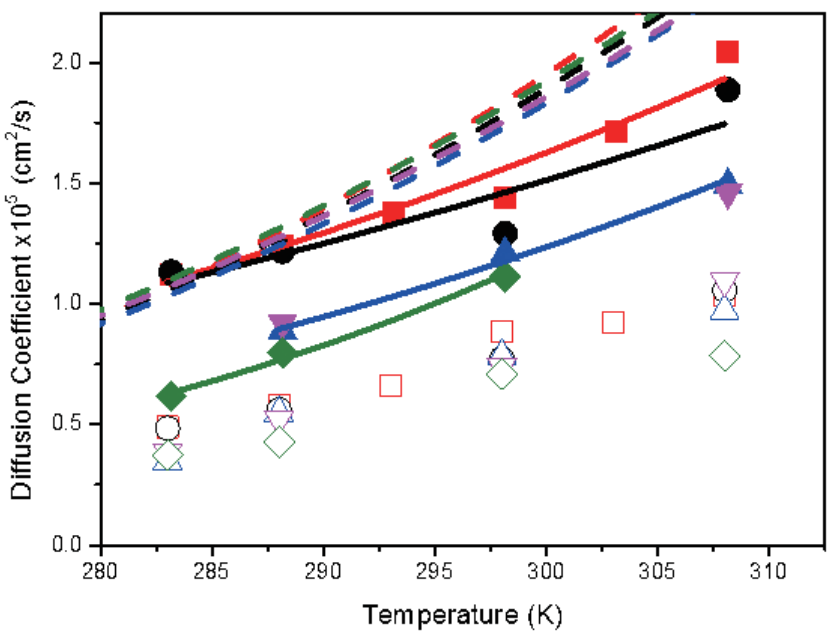

Fig. 6. Diffusion coefficients of methane in water and in brine determined by Raman spectroscopy experiments and MD simulations. Experimental results of diffusion coefficient of methane in pure water ( $\boldsymbol{\square}$, red solid and dashed line), in $3.5 \mathrm{wt} \% \mathrm{NaCl}$ solution ( $\bullet$, black solid and dashed line), in $6.0 \mathrm{wt} \% \mathrm{NaBr}$ solution ( $\boldsymbol{\Delta}$, blue solid and dashed line), in $8.6 \mathrm{wt} \% \mathrm{NaI}$ solution ( $\boldsymbol{\nabla}$, magenta dashed line), and in $6.5 \mathrm{wt} \% \mathrm{CaCl}_{2}$ solution $(\triangleleft$, green solid and dashed line). MD simulation results of diffusion coefficient of methane in $3.5 \mathrm{wt} \% \mathrm{NaCl}$ solution $(\mathrm{O})$, in $6.0 \mathrm{wt} \% \mathrm{NaBr}$ solution $(\Delta)$, in $8.6 \mathrm{wt} \% \mathrm{NaI}$ solution $(\nabla)$, and in $6.5 \mathrm{wt} \% \mathrm{CaCl}_{2}$ solution $(\diamond)$. The solid line stand for the calculated results from Eq. (8) for the methane diffusion coefficients in pure water and in brine. The dashed lines represent the prediction results from the correlation of Hayduk and Laudie (1974) for the methane diffusion coefficients in pure water and in brine.

Table 3. Regressed parameters of the diffusion coefficient of methane in pure water and brine for Eq. (8).

\begin{tabular}{cccc}
\hline Brine & $\mathbf{A}$ & $\mathbf{B}$ & $\mathbf{R}^{2}$ \\
\hline Pure Water & $-1990 \pm 213$ & $7.11 \pm 0.72$ & 0.945 \\
$3.5 \mathrm{wt} \% \mathrm{NaCl}$ & $-1670 \pm 521$ & $5.98 \pm 1.77$ & 0.755 \\
$6.5 \mathrm{wt} \% \mathrm{CaCl}_{2}$ & $-3260 \pm 332$ & $11.0 \pm 1.15$ & 0.979 \\
$6.0 \mathrm{wt} \% \mathrm{NaBr}$ & $-2320 \pm 211$ & $7.94 \pm 0.71$ & 0.984 \\
\hline
\end{tabular}

consist to previous result. And the results in brine reveal that the diffusion coefficient of methane will decrease when the electrolyte is added into water. At the same mole fraction, the diffusion of methane in $\mathrm{CaCl}_{2}$ aqueous is lower than that in $\mathrm{NaCl}$ aqueous. The result from molecular dynamic also obtain the same tendency on the effect of temperature and addition of electrolyte.

Acknowledgements This study was supported by the Ministry of Science and Technology of Taiwan via Grants: 1053113-M-002-006, 104-3113-M-002-006, and 103-3113-M002-006.

\section{REFERENCES}

Anderson, R., A. Chapoy, H. Haghighi, and B. Tohidi, 2009: Binary ethanol-methane clathrate hydrate formation in the system $\mathrm{CH}_{4}-\mathrm{C}_{2} \mathrm{H}_{5} \mathrm{OH}-\mathrm{H}_{2} \mathrm{O}$ : Phase equilibria and compositional analyses. J. Phys. Chem. C, 113, 1260212607, doi: 10.1021/jp9021536. [Link]

Barrer, R. M. and D. J. Ruzicka, 1962a: Non-stoichiometric clathrate compounds of water. Part 3.--Inclusion energies and constants in the small cavities of structure II. Trans. Faraday Soc., 58, 2253-2261, doi: 10.1039/ TF9625802253. [Link]

Barrer, R. M. and D. J. Ruzicka, 1962b: Non-stoichiometric clathrate compounds of water. Part 4.-Kinetics of formation of clathrate phases. Trans. Faraday Soc., 58, 2262-2271, doi: 10.1039/tf9625802262. [Link]

Berendsen, H. J. C., D. van der Spoel, and R. van Drunen, 1995: GROMACS: A message-passing parallel molecular dynamics implementation. Comput. Phys. Comm., 91, 43-56, doi: 10.1016/0010-4655(95)00042-E. [Link]

Bird, R. B., W. E. Stewart, and E. N. Lightfoot, 2007: Transport Phenomena, John Wiley \& Sons, 905 pp.

Bodnar, L. H. and D. M. Himmelblau, 1962: Continuous measurement of diffusion coefficients of gases in liquids using glass scintillators. Int. J. Appl. Radiat. Isot., 13, 1-6, doi: 10.1016/0020-708X(62)90159-X. [Link]

Caumon, M.-C., P. Robert, E. Laverret, A. Tarantola, A. Randi, J. Pironon, J. Dubessy, and J.-P. Girard, 2014: Determination of methane content in $\mathrm{NaCl}-\mathrm{H}_{2} \mathrm{O}$ fluid 
inclusions by Raman spectroscopy. Calibration and application to the external part of the Central Alps (Switzerland). Chem. Geol., 378-379, 52-61, doi: 10.1016/j. chemgeo.2014.03.016. [Link]

Christiansen, R. L. and E. D. Sloan, 1994: Mechanisms and kinetics of hydrate formation. Ann. New York Acad. Sci., 715, 283-305, doi: 10.1111/j.1749-6632.1994. tb38841.x. [Link]

Chu, C.-K., P.-C. Chen, Y.-P. Chen, S.-T. Lin, and L.-J. Chen, 2015: Inhibition effect of 1-ethyl-3-methylimidazolium chloride on methane hydrate equilibrium. J. Chem. Thermodyn., 91, 141-145, doi: 10.1016/j. jct.2015.07.040. [Link]

Chu, C.-K., S.-T. Lin, Y.-P. Chen, P.-C. Chen, and L.-J. Chen, 2016: Chain length effect of ionic liquid 1-alkyl-3-methylimidazolium chloride on the phase equilibrium of methane hydrate. Fluid Phase Equilib., 413, 57-64, doi: 10.1016/j.fluid.2015.10.007. [Link]

Dalmazzone, D., M. Kharrat, V. Lachet, B. Fouconnier, and D. Clausse, 2002: DSC and PVT measurements. J. Therm. Anal. Calorimetry, 70, 493-505, doi: 10.1023/a:1021632709287. [Link]

Darden, T., D. York, and L. Pedersen, 1993: Particle mesh Ewald: An $\mathrm{N} \cdot \log (\mathrm{N})$ method for Ewald sums in large systems. J. Chem. Phys., 98, 10089-10092, doi: 10.1063/1.464397. [Link]

Duan, Z. and S. Mao, 2006: A thermodynamic model for calculating methane solubility, density and gas phase composition of methane-bearing aqueous fluids from 273 to $523 \mathrm{~K}$ and from 1 to 2000 bar. Geochim. Cosmochim. Acta, 70, 3369-3386, doi: 10.1016/j. gca.2006.03.018. [Link]

Egorov, A. V., K. Crane, P. R. Vogt, A. N. Rozhkov, and P. P. Shirshov, 1999: Gas hydrates that outcrop on the sea floor: Stability models. Geo-Mar. Lett., 19, 68-75, doi: 10.1007/s003670050094. [Link]

Gabitto, J. F. and C. Tsouris, 2010: Physical properties of gas hydrates: A review. J. Therm., 2010, 1-12, doi: 10.1155/2010/271291. [Link]

Gubbins, K. E., K. K. Bhatia, and R. D. Walker, 1966: Diffusion of gases in electrolytic solutions. AIChE J., 12, 548-552, doi: 10.1002/aic.690120328. [Link]

Guo, H. R., Y. Chen, W. J. Lu, L. L. Li, and M. H. Wang, 2013: In situ Raman spectroscopic study of diffusion coefficients of methane in liquid water under high pressure and wide temperatures. Fluid Phase Equilib., 360, 274-278, doi: 10.1016/j.fluid.2013.09.051. [Link]

Gupta, A., J. Lachance, E. D. Sloan, and C. A. Koh, 2008: Measurements of methane hydrate heat of dissociation using high pressure differential scanning calorimetry. Chem. Eng. Sci., 63, 5848-5853, doi: 10.1016/j. ces.2008.09.002. [Link]

Handa, Y.P., 1986: Compositions, enthalpies of dissociation, and heat capacities in the range 85 to $270 \mathrm{~K}$ for clathrate hydrates of methane, ethane, and propane, and enthalpy of dissociation of isobutane hydrate, as determined by a heat-flow calorimeter. J. Chem. Thermodyn., 18, 915921, doi: 10.1016/0021-9614(86)90149-7. [Link]

Hayduk, W. and H. Laudie, 1974: Prediction of diffusion coefficients for nonelectrolytes in dilute aqueous solutions. AIChE J., 20, 611-615, doi: 10.1002/ aic.690200329. [Link]

Hester, K. C., Z. Huo, A. L. Ballard, C. A. Koh, K. T. Miller, and E. D. Sloan, 2007: Thermal expansivity for sI and sII clathrate hydrates. J.Phys. Chem. B, 111, 88308835, doi: 10.1021/jp0715880. [Link]

Himmelblau, D. M., 1964: Diffusion of dissolved gases in liquids. Chem. Rev., 64, 527-550, doi: 10.1021/ cr60231a002. [Link]

Hsieh, M.-K., W.-Y. Ting, Y.-P. Chen, P.-C. Chen, S.-T. Lin, and L.-J. Chen, 2012: Explicit pressure dependence of the Langmuir adsorption constant in the van der Waals-Platteeuw model for the equilibrium conditions of clathrate hydrates. Fluid Phase Equilib., 325, 80-89, doi: 10.1016/j.fluid.2012.04.012. [Link]

Hsieh, M. T. and S. T. Lin, 2011: A predictive model for the excess gibbs free energy of fully dissociated electrolyte solutions. AIChE J., 57, 1061-1074, doi: 10.1002/ aic.12325. [Link]

Incropera, F. P., D. P. DeWitt, T. L. Bergman, and A. S. Lavine, 2007: Fundamentals of Heat and Mass Transfer, John Wiley, 997 pp.

Jähne, B., G. Heinz, and W. Dietrich, 1987: Measurement of the diffusion coefficients of sparingly soluble gases in water. J. Geophys. Res., 92, 10767-10776, doi: 10.1029/JC092iC10p10767. [Link]

Jorgensen, W. L., D. S. Maxwell, and J. Tirado-Rives, 1996: Development and testing of the OPLS all-atom force field on conformational energetics and properties of organic liquids. J. Am. Chem. Soc., 118, 11225-11236, doi: 10.1021/ja9621760. [Link]

Juan, Y. W., M. Tang, L. J. Chen, S. T. Lin, P. C. Chen, and Y. P. Chen, 2015: Measurements for the equilibrium conditions of methane hydrate in the presence of cyclopentanone or 4-hydroxy-4-methyl-2-pentanone additives. Fluid Phase Equilib., 386, 162-167, doi: 10.1016/j.fluid.2014.11.018. [Link]

Kashchiev, D. and A. Firoozabadi, 2002a: Driving force for crystallization of gas hydrates. J. Cryst. Growth, 241, 220-230, doi: 10.1016/S0022-0248(02)01134-X. [Link]

Kashchiev, D. and A. Firoozabadi, 2002b: Nucleation of gas hydrates. J. Cryst. Growth, 243, 476-489, doi: 10.1016/ S0022-0248(02)01576-2. [Link]

Kashchiev, D. and A. Firoozabadi, 2003: Induction time in crystallization of gas hydrates. J. Cryst. Growth, 250, 499-515, doi: 10.1016/S0022-0248(02)02461-2. [Link] 
Kestin, J., H. E. Khalifa, Y. Abe, C. E. Grimes, H. Sookiazian, and W. A. Wakeham, 1978a: Effect of pressure on the viscosity of aqueous sodium chloride solutions in the temperature range $20-150^{\circ} \mathrm{C}$. J. Chem. Eng. Data, 23, 328-336, doi: 10.1021/je60079a011. [Link]

Kestin, J., M. Sokolov, and W. A. Wakeham, 1978b: Viscosity of liquid water in the range $-8^{\circ} \mathrm{C}$ to $150^{\circ} \mathrm{C}$. J. Phys. Chem. Ref. Data, 7, 941-948, doi: 10.1063/1.555581. [Link]

Laliberté, M., 2007: Model for Calculating the Viscosity of Aqueous Solutions. J. Chem. Eng. Data, 52, 321-335, doi: 10.1021/je0604075. [Link]

Lin, L., H. Guo, X. Hao, and Y. Huang, 2014: Determination of diffusion coefficients of ethane in water at high pressure and temperature with in-situ Raman spectroscopy. Earth Sci. J. China Univ. Geosci., 39, doi: 10.3799/dqkx.2014.151. [Link]

Lin, S., W. C. Hsieh, Y. C. Lim, T. F. Yang, C. S. Liu, and Y. Wang, 2006: Methane migration and its influence on sulfate reduction in the Good Weather Ridge region, South China Sea continental margin sediments. Terr. Atmos. Ocean. Sci., 17, 883-902, doi: 10.3319/ TAO.2006.17.4.883(GH). [Link]

Liu, N., C. Aymonier, C. Lecoutre, Y. Garrabos, and S. Marre, 2012: Microfluidic approach for studying $\mathrm{CO}_{2}$ solubility in water and brine using confocal Raman spectroscopy. Chem. Phys. Lett., 551, 139-143, doi: 10.1016/j.cplett.2012.09.007. [Link]

Lu, W. J., I. M. Chou, R. C. Burruss, and M. Z. Yang, 2006: In situ study of mass transfer in aqueous solutions under high pressures via Raman spectroscopy: A new method for the determination of diffusion coefficients of methane in water near hydrate formation conditions. Appl. Spectros., 60, 122-129, doi: 10.1366/000370206776023278. [Link]

Lu, W. J., H. R. Guo, I. M. Chou, R. C. Burruss, and L. L. Li, 2013: Determination of diffusion coefficients of carbon dioxide in water between 268 and $473 \mathrm{~K}$ in a high-pressure capillary optical cell with in situ Raman spectroscopic measurements. Geochim. Cosmochim. Acta, 115, 183-204, doi: 10.1016/j.gca.2013.04.010. [Link]

Maharajh, D. M. and J. Walkley, 1973: The temperature dependence of the diffusion coefficients of $\mathrm{Ar}, \mathrm{CO}_{2}, \mathrm{CH}_{4}$, $\mathrm{CH}_{3} \mathrm{Cl}, \mathrm{CH}_{3} \mathrm{Br}$, and $\mathrm{CHCl}_{2} \mathrm{~F}$ in water. Can. J. Chem., 51, 944-952, doi: 10.1139/v73-140. [Link]

Manakov, A. Y., A. Y. Likhacheva, V. A. Potemkin, A. G. Ogienko, A. V. Kurnosov, and A. I. Ancharov, 2011: Compressibility of gas hydrates. ChePhysChem, 12, 2476-2484, doi: 10.1002/cphc.201100126. [Link]

Natarajan, V., P. R. Bishnoi, and N. Kalogerakis, 1994: Induction phenomena in gas hydrate nucleation. Chem. Eng. Sci., 49, 2075-2087, doi: 10.1016/0009-2509(94) E0026-M. [Link]
Ning, F. L., K. Glavatskiy, Z. Ji, S. Kjelstrup, and T. J. H. Vlugt, 2015: Compressibility, thermal expansion coefficient and heat capacity of $\mathrm{CH}_{4}$ and $\mathrm{CO}_{2}$ hydrate mixtures using molecular dynamics simulations. Phys. Chem. Chem. Phys., 17, 2869-2883, doi: 10.1039/ C4CP04212C. [Link]

Pinder, K. L., 1965: A kinetic study of the formation of the tetrahydrofuran gas hydrate. Can. J. Chem. Eng., 43, 271-274, doi: 10.1002/cjce.5450430510. [Link]

Pratt, K. C., D. H. Slater, and W. A. Wakeham, 1973: A rapid method for the determination of diffusion coefficients of gases in liquids. Chem. Eng. Sci., 28, 19011903, doi: 10.1016/0009-2509(73)85074-2. [Link]

Pronk, S., S. Páll, R. Schulz, P. Larsson, P. Bjelkmar, R. Apostolov, M. R. Shirts, J. C. Smith, P. M. Kasson, D. van der Spoel, B. Hess, and E. Lindahl, 2013: GROMACS 4.5: A high-throughput and highly parallel open source molecular simulation toolkit. Bioinformatics, 29, 845-854, doi: 10.1093/bioinformatics/btt055. [Link]

Rehder, G., S. H. Kirby, W. B. Durham, L. A. Stern, E. T. Peltzer, J. Pinkston, and P. G. Brewer, 2004: Dissolution rates of pure methane hydrate and carbondioxide hydrate in undersaturated seawater at 1000-m depth. Geochim. Cosmochim. Acta, 68, 285-292, doi: 10.1016/j.gca.2003.07.001. [Link]

Rydzy, M. B., J. M. Schicks, R. Naumann, and J. Erzinger, 2007: Dissociation enthalpies of synthesized multicomponent gas hydrates with respect to the guest composition and cage occupancy. J. Phys. Chem. B, 111, 9539-9545, doi: 10.1021/jp0712755. [Link]

Sachs, W., 1998: The diffusional transport of methane in liquid water: Method and result of experimental investigation at elevated pressure. J. Pet. Sci. Eng., 21, 153164, doi: 10.1016/s0920-4105(98)00048-5. [Link]

Schmelzer, J. W. P., E. D. Zanotto, and V. M. Fokin, 2005: Pressure dependence of viscosity. J. Chem. Phys., 122, doi: 10.1063/1.1851510. [Link]

Sloan, E. D., 1998: Gas Hydrates: Review of Physical/ Chemical Properties. Energ. Fuel., 12, 191-196, doi: 10.1021/ef970164+. [Link]

Sloan, E. D. and C. A. Koh, 2007: Clathrate Hydrates of Natural Gases, CRC Press, 752 pp.

Sun, Q., 2009: The Raman $\mathrm{OH}$ stretching bands of liquid water. Vib. Spectros., 51, 213-217, doi: 10.1016/j.vibspec.2009.05.002. [Link]

Tham, M. J., K. K. Bhatia, and K. F. Gubbins, 1967: Steadystate method for studying diffusion of gases in liquids. Chem. Eng. Sci., 22, 309-311, doi: 10.1016/00092509(67)80117-9. [Link]

Tham, M. K. and K. E. Gubbins, 1972: Effect of salts on the diffusion of dissolved non-electrolytes. J. Chem. Soc., Faraday Trans. 1, 68, 1339-1346, doi: 10.1039/ f19726801339. [Link] 
Van Der Spoel, D., E. Lindahl, B. Hess, G. Groenhof, A. E. Mark, and H. J. C. Berendsen, 2005: GROMACS: Fast, flexible, and free. J. Comput. Chem., 26, 17011718, doi: 10.1002/jcc.20291. [Link]

Van Der Waals, J. H. and J. C. Platteeuw, 1958: Clathrate solutions. In: Prigogine, I. (Ed.), Advances in Chemical Physics, Volume 2, John Wiley \& Sons, Inc., Hoboken, NJ, USA, 1-57, doi: 10.1002/9780470143483. ch1. [Link]

Vysniauskas, A. and P. R. Bishnoi, 1983: A kinetic study of methane hydrate formation. Chem. Eng. Sci., 38, 10611072, doi: 10.1016/0009-2509(83)80027-X. [Link]

Welty, J., C. E. Wicks, G. L. Rorrer, and R. E. Wilson, 2007: Fundamentals of Momentum, Heat, and Mass
Transfer, Wiley, $740 \mathrm{pp}$.

Witherspoon, P. A. and D. N. Saraf, 1965: Diffusion of methane, ethane, propane, and n-butane in water from 25 to $43^{\circ}$. J. Phys. Chem., 69, 3752-3755, doi: 10.1021/ j100895a017. [Link]

Wopenka, B. and J.D. Pasteris, 1986: Limitations to quantitative analysis of fluid inclusions in geological samples by laser Raman microprobe spectroscopy. Appl. Spectros., 40, 144-151, doi: 10.1366/0003702864509592. [Link]

Wu, J.-Y., L.-J. Chen, Y.-P. Chen, and S.-T. Lin, 2016: Molecular dynamics study on the nucleation of methane + tetrahydrofuran mixed guest hydrate. Phys. Chem. Chem. Phys., 18, 9935-9947, doi: 10.1039/ C5CP06419H. [Link] 